\title{
SOME CORRELATIONS OF CLIMATIC AND CULTURAL CHANGE IN EASTERN NORTH AMERICAN PREHISTORY
}

\author{
J. B. Griffin \\ University of Michigan, Ann Arbor, Mich.
}

There is thus far relatively little direct evidence for climatic change from archaeological sites in the eastern United States. Archaeologists have considered for many years that the dividing line between eastern and western is the eastern side of the Rocky Mountains. This whole area then, has become a convenient unit of prehistoric studies because of the obvious connections and similarities at all known time periods and all of the cultural levels. Since A. D. Krieger, in his paper in this volume, emphasizes the initial occupation in North America, my attention will be primarily devoted to the last 4000 to 5000 years.

Before one can interpret cultural changes as resulting from climatic variation it is highly desirable to have one's prehistoric house in reasonable order. Sound chronological and stratigraphic sequences need to be developed over a wide area, and cultural complexes need to be carefully defined in local areas and in their correct and reasonably precise temporal position in order to observe the effects of climatic change on cultural behavior. Not only is a sound and laboriously obtained archaeological framework necessary, but there needs to be a sound corpus of data regarding floral and faunal changes, of soil zones, and of other climatic indicators in general ecological areas or zones. The pollen studies of the past 30 years have been a great help, and radiocarbon dating is providing an increasingly accurate chronological scale.

Three years ago, while working on a paper on the prehistory of the Winnebago tribe of Wisconsin (Griffin, 1960b), I developed the thesis that the observed cultural decline in the Upper Mississippi Valley of the Winnebago and their ancestors could be explained, at least to some degree, as the result of a climatic deterioration that corresponded to that accurately documented in Northern Europe and Greenland from about A.D. 1200 to 1700. Beginning a few hundred years before A.D. 1000 there developed in the East St. Louis area an agricultural, sedentary culture type that is a regional expression of an increasing emphasis on agriculture known in much of the eastern area as the Mississippi culture (Griffin, 1952). The Old Village complex of Mississippi culture in the St. Louis area exerted a strong influence to the north and northwest, up the Illinois, Mississippi, and the Missouri valleys. It is certain that there was a strong movement of people into southern and western Wisconsin by about A.D. 700 to 800 (M-1037) and into eastern Minnesota, taking with them their customary cultural characteristics and their predominantly agricultural economy. Somewhat similar but apparently less strong influences moved into northwest Iowa and southeastern South Dakota.

From the archaeological evidence, we had known for some time that the late prehistoric and early historic culture of the Upper Mississippi area, called Oneota, was a descendant of the Old Village tradition (Griffin, 1943, p. 302) that had shifted away from a marked dependence on agriculture to a heavier 
emphasis on hunting, and that there was a marked drop in cultural level. This period of gradual decline can now be clearly seen as occurring in the A.D. 1300 to 1650 time period. Preliminary reports of the Mill Creek culture in northwest Iowa also indicate a gradual shift toward increased emphasis on hunting from the Old Village influenced lower levels of deep middens, to the upper and later levels that should date from A.D. 1400 to 1600.

In the lower Great Lakes and New York area an increasing dependence on agriculture and a more sedentary way of life begins during the A.D. 700 to 900 period. This regional development does not go into a decline but instead seems to reach a climax in the Iroquoian culture type in lower Ontario and New York between A.D. 1400 to 1600 . It is suggested that the modifying effect of the Great Lakes on this area was sufficient to prevent a decline in effectiveness of agricultural crops and thus sustained the Iroquoian economy. Such an effect is in operation now on the present flora (Soper, 1956).

In considering the archaeological evidence from the plains it is necessary to keep in mind the marked division in that area between the eastern and western plains. This division is recognized in vegetation and animal life, which reflect climatic differences, primarily rainfall, which decreases markedly from Omaha to Denver. By A.D. 700 to 900 ceramic producing and partially agricultural people have moved, or their culture pattern has spread, from the eastern plains of Kansas and Nebraska into eastern Colorado and the Texas and Oklahoma panhandles. Here they come into contact with peoples moving eastward from the Southwest culture center. From A.D. 900 to 1300 there are settled agricultural villages in the high plains located on well developed humus zones that overlie soils of a drier period (Wedel, 1941, p. 19). Between A.D. 1300 to 1500 there is a marked withdrawal of these people to central and eastern South Dakota, Nebraska, Kansas, and Oklahoma (Wedel, 1953, figure 2). In this area they are strongly concentrated in their agricultural villages along the major stream valleys with sources in the Rocky Mountains. The sites in the high plains which have been abandoned, are covered by wind blown soils. This is not the case with the abandoned sites of the same period in the eastern plains.

Turning briefly to the Southwest we see, on maps prepared by Stanley Stubbs, that the period from A.D. 700 to 1200 is marked by a great expansion of agricultural village settlements from an initial center in the four corners area, to occupy much of Utah as far as the area of Great Salt Lake, into eastern Colorado and eastern New Mexico (Jennings, 1955, pp. 64 to 66). Shortly before A.D. 1200 , a marked retraction sets in, so that by the time of the Spanish penetration into the Southwest the Pueblo agricultural Indians were concentrated along the Rio Grande and in other local areas where there was arable land and a dependable water supply from high-altitude sources. A similar expansion and retraction took place in southern Arizona where a striking prehistoric culture, the Hohokam, flourished and developed an extensive irrigation system. It should also be noted that in northwestern Mexico, along the eastern slope of the Sierra Madre range, there was a notable growth of agricultural settlements in the 700 to 1350 period, and that during the following centuries there was a marked abandonment of these sedentary sites (Kelley, 1956, p. 132). There are a 
number of significant evidences of erosion in the Southwest from 1200 to 1700 in the alluvial deposits built up during the general period of alluviation of the A.D. 700 to A.D. 1100 period.

It is believed that the period from A.D. 700 to 1200 in the Southwest and western plains is a period of more adequate and equitable distribution of rainfall that would allow the growth and expansion of argicultural communities. The temperature conditions might or might not be significantly different from those of the present. In this same period there seems to be a warmer climate in the Upper Mississippi Valley and Great Lakes which allows the settled agricultural populations to move northward into locations near the present border of effective corn agriculture.

The 1200 to 1700 period in the Great Lakes and northeast is believed to be relatively cooler and with a shorter growing season. It is probably also somewhat moister. It is my belief that minor changes in pollen diagrams from Minnesota to Maine reflect this relatively colder period. Minor glacial advances are recorded for this period, and the recent sea-level rise is from the lower levels reached because of glacial growth. As observed above, it is a period of increasing cold and storminess in Northwestern Europe that is historically documented. In the Southwest and western plains it is evident that this period is one of increased dryness and of marked erosion.

By dropping backward another 1000 years we can see a similar sequence that parallels that from A.D. 700 to 1700 . Between approximately 300 B.C. to A.D. 300 there developed in the Ohio and Illinois areas a culture called Hopewellian that is sedentary, ceramic-using and, to some degree, agricultural (Griffin, 1958). From the central Illinois area, Hopewell people and cultural influences move into northern Indiana and Michigan, to as far north as the Muskegon-Saginaw line. There is also a movement up the Mississippi into Wisconsin and eastern Minnesota, as far as the mouth of the Minnesota and to Green Bay. Cultural spread also takes place to eastern Kansas, Nebraska, and northeastern Oklahoma. The westward movement of people on a Hopewellian level reaches western Kansas and perhaps to eastern Colorado.

The Hopewellian development was a remarkable one in many ways, and it it was their cultural products, earthworks, and elaborate burial mounds that was largly responsible for the term Mound Builders. That term, incidentally, was abandoned by archaeologists many years ago. For many years archaeologists have been puzzled by the disappearance of the Hopewellian culture. Recently we have been able to recognize that it did not suddenly disappear by conquest or migration but that, instead, it gradually declined into a simpler and. less spectacular cultural form. In every area where it was dominant, from eastern Ohio to Kansas City and from Illinois into Wisconsin and Michigan, there is a gradual change into Late Woodland Culture expressions which can now be accurately dated from A.D. 300 to 400 to 700 to 1000 . In the areas north and east of the Mississippi cultures this general Late Woodland Culture was maintained to the period of European exploration and colonization.

Last spring I prepared a short paper postulating that the Hopewellian growth and spread to the north coincided with the evidence from northwestern Europe of a relatively warm-dry period, and with evidence for a sea-level rise representing a general climatic moderation (Griffin, 1960a). This same period of 300 
B.C. to A.D. 300 marks the initial development in the Southwest of small, settled village agriculturists in southwestern New Mexico and southeastern Arizona, and of the period of growth of the Basketmaker II culture in the four-corners area of the Southwest. At present I am not aware of much evidence of a climatic deterioration in the Southwest in the next 400 to 500 years, but Antevs (1955, p. 330) has called attention to the Whitewater drought and erosion in the Southwest, and this is also reflected in the tree-ring pattern. At some sites in the western plains, of the Hopewellian level, which is on a welldeveloped humus zone, there is a soil cover over the village site indicating a period of markedly drier climate before the later humus soil of the A.D. 800 to 1200 period (Wedel, 1941).

The alternating climatic pattern described for the period of A.D. 700 to 1700 is thus foreshadowed by that from about 300 B.C. to A.D. 700 in the Southwest, in the western plains, and the Upper Mississippi Valley-Great Lakes. A relatively mild climate in the latter area coincides with effective rainfall for vegetation and agriculture in the Southwest and western plains. A colder climatic regime in the north and northeast coincides with evidences of drought and erosion in the Southwest and evidence of wind blown soils in the western plains.

There is very little direct evidence on climate from archaeological sites in the period from 2000 B.C. to 300 B.C. in the eastern United States. If the pattern of alternating cool and warm periods continues in its suggested regularity into the past, then the period from ca. 800 to 300 B.C. should be relatively cool; from 1300 to 800 B.C., relatively warm; 1800 to 1300 B.C., relatively cold and, from 2300 to 1800 B.C., relatively warm. We should also find, in the Southwest and western plains, indications of alternating drought and alluvial deposition. The latter accompanied by a more favorable rainfall pattern for vegetation.

The evidence from the Southwest is not clear, uniform, and accurately dated in the majority of cases. There are also gaps in the areas studied and either in the formations themselves or in the interpretive record. It is also true that if erosion is operative in a particular local area that such eroded material will be deposited in another area. Antevs (1955, figure 93) has called the Fairbank Drought a period of drought and erosion dated at 500 B.C. There are other loci in the Southwest and the high plains that indicate that this general period is relatively dry. The Hopewellian period humus zone occupation in western Kansas of about A.D. 100 to 200 is underlain by a sterile grey windblown (?) soil that may well belong to the 800 to 300 B.C. period of drought.

The Fairbank Drought is preceded by a period of alluvial and colluvial deposition that is placed on a recent correlation about 200 years on each side of 1000 B.C. (Haynes and Agogino, p. 21). I know of no supporting evidence from the Northeast to indicate that the period of 1300 to 800 B.C. actually has a warmer climate. There is, however, a warm dry spell clearly recorded in England at this time (Godwin and Willis, 1960, p. 66, Q-389), and the same general conditions are expectable in the Great Lakes. There is a raised beach line 4 feet above sea level in New Zealand that is documented by Schofield (1960, p. 479), and this should be the correct period for the Younger Peron Terrace of Fairbridge (1958). This is a cultural period in the Great Lakes and 
Northeast in which we recognize a striking development of burial ceremonialism spread from southern New England to the northern Wisconsin area. Some of the cultural characteristics and, perhaps, people as well may have moved south into Illinois and the Ohio Valley during the cold period of 800 to 300 B.C. and, if so, they helped to stimulate the striking cultural development in that area of the next warm period: one that, however, is clearly forming to the south during the 800 to 300 B.C. level. This cool-moist period in England is represented by the trackways of the Late Bronze Age in Somerset dated between 870 and 310 B.C. that were laid to allow crossing of flooded bogs (Godwin and Willis, 1959 and 1960). The earlier date is also that of the Grenzhorizont.

An excellent example of a minor effect on cultural patterns in the Archaic stage in the Southeast may be seen in the headwaters of the St. Johns River, and on Indian River in east-central Florida, where sea-level changes caused minor population displacement but no significant cultural change. In this area the Late Archaic preceramic complex and the early ceramic period is found on the relatively dry land surface of the Melbourne-Van Valkenburg interval. Rouse (1951, pp. 239-263) has an excellent summary in which the relations of the sites to changes in sea level and environment are emphasized. He believed, and still believes (personal communication, January 1961) that the date of the early ceramic level corresponds to approximately 1000 B.C. I am not certain, however, as to the precise correlation of Rouse's cultural and climatic interpretations with the fluctuations of sea level of Fairbridge. The culmination of the Younger Peron Terrace is given about 1700 B.C. which is probably too early for the Florida data of Rouse. Certainly, radiocarbon dating is desirable for the specific cultural complexes involved. The sea level changes that have been documented thus far will certainly be revised and probably increased as new and more accurate assessments and interpretations are made. I believe that something is wrong with the spread of years given by Fairbridge for theYounger Peron Terrace. The sea-level rise of Rouse's early ceramic period is probably one that occurs about 1200 B.C.

I shall skip over the postulated cold period in the north from 1800 to 1300 B.C. for which there is some documentation in the form of lowered sea levels, peat deposits, and trackways in England, and a presumed, on my part, drought and erosion in the Southwest. For the postulated warm period in the north from ca. 2300 to 1800 B.C. there is a considerable amount of confirmatory evidence. The post-Glacial rise to the period of maximum warmth seems to reach its peak in this period with the most northern extent of the deciduous forest. The general post-Glacial northward movement of the flora with its accompanying animal life allowed the northward movement of prehistoric culture complexes that had developed in this ecological zone, in the Ohio Valley, in the Central Mississippi Valley, and along the Middle Atlantic Coast. It is quite clear that this northward movement of culture did take place and that from Wisconsin, across the lower Peninsula of Michigan, across Ontario, and into New York and New England, there is a marked flowering of what we call Archaic cultures in this Late Archaic period. This development marks the beginning of the Old Copper Culture in the western Great Lakes and of the development of the Lamoka, Laurentian, and coastal cultures of the Northeast. 
These cultures did not originate in or develop in a "boreal" forest zone, and only rarely did they move into one.

For this general cultural level we have recorded at some sites the presence of acorns and hickory nuts. We know that a deciduous forest covers the area delineated above by this time. The importance of these nuts, as food, is emphasized by the numbers of grinding stones used for their preparation in the Lamoka culture (Ritchie, 1932). The most important food supply, however, appears to have been derived from hunting and fishing. During this period of time, 2500 to 2000 B.C., we find a rather stable occupation by Indian groups at favorable sites over a fairly long period. A specific indication of Lamoka period and climate is the presence of the fresh-water snail (Galba catascopium) in the bottom level of the Lotus Point Site, N. Y., with a complex of the Lamoka culture (Ritchie, 1958, p. 33). The habitat of this snail is such that it is suggested that the Hudson River level was 10 to 12 feet higher than at present. The lower levels of the river site, with an "early" Lamoka occupation, were interpreted geologically as belonging to a period of higher water level in the Hudson (ibid., p. 44). This would seem to be best interpreted as that of the high water stage of about 2000 to 1800 B.C. represented by raised beaches in Algeria and England, or, less likely, the Older Peron Terrace of 3100 B.C. (Fairbridge, 1958).

The date for the sub-Boston Boylston Street fish weir and its burial by marine silts is presented in this paper as representing the period of a major rise in sea level, about 2000 B.C. Underlying the fish weir, which was built in the mud flat and marsh land, was a 9-inch layer of fresh-water peat, which has a possible shift from a drier phase in the lower section and a moister phase toward the top (Benninghoff, 1942, p. 104). A sample of this peat from an unspecified section of the deposit is dated at 3762 B.C. $\pm 500(\mathrm{C}-417)$. One of the preserved stakes, of an estimated 65,000 , has a date of $4500 \pm 130$ or ca. 2500 B.C. About 4 feet above the fish weir, in marine silts, was a stream rafted stump that has been given a date of 1896 B.C. \pm 390 (C-418). The exact meaning of these dates, in terms of the complex relationship between sea and land levels in the Boston area, is left to those who have actively participated in its interpretation. It is inferred here that the sea was rising and that its rise reflects that observed in other areas. It is clear that the vegetational picture of the lower peat and of the time of the weir indicates a climate comparable to, and then warmer than, that of the present time (Barghoorn, 1959, pp. 109 to 110 ).

The cultural pattern of the fish-weir builders would be very close to that of the Late Archaic occupants of the Wapanucket site near Middleboro, Mass. (Robbins, 1959), where three radiocarbon dates (M-764, 969, and W-363) place the period at 2300 B.C. From other evidence in southern New England we know that this period marks a climax of the Archaic occupations in terms of stability and number of sites. This period of 3000 to 2000 B.C., of northward movement of developed Archaic complexes, is also the one in which there is good reason on archaeological grounds to believe that the Minnesota Man or Lady belongs. 


\section{Summary}

The above discussion has focused attention on some proposed climatic fluctuations in the southwestern United States, the upper Mississippi ValleyGreat Lakes, northeastern United States and northwestern Europe. These alternations of climatic conditions appear to occur between about 500 to 600 years. The period chosen for discussion of the last 4000 years is one for which we have some adequate documentation and for some of which we have suggestive historical records. The presentation made in this paper should be viewed as schematic and provocative. It will need more adequate documentation and temporal control to be adopted as a working hypothesis for intensive study.

The approximately 550 years periodicity of climatic change proposed above is one recognized by other students and for which there is evidence in other areas and at other times. In Denmark and North Germany, Barendsen et al., (1957, Figure 1) have recently presented tight radiocarbon dating for minor climatic fluctuations of ca. 550 years, representing changes from continental to maritime climates during the period from ca. 11,660 B.C. to 8500 B.C. These alternations represent climatic fluctuations of a somewhat similar pattern in the minor advances and retreats of the glaciers during their gradual withdrawal from the upper Great Lakes and lower Canada.

The implication of the periodic changes in climatic patterns for the three areas discussed in this paper is that the changes were probably brought about by changes in the circulation pattern of the earth's atmosphere. I have discussed this question with certain meterologists who will remain nameless, and thus blameless, for any misunderstanding of their views. One suggestion has been that cool-moist conditions in the northern and northeastern United States and evidence of drought in the Southwest is probably produced by a lowlatitude zonal circulation that also causes climatic stress, such as the development of heavy storms along the eastern part of the country and in the North Atlantic and Europe. On the other hand a high-latitude zonal circulation would produce warm and relatively dry conditions in the north and northeast and would bring greater summer precipitation in the Southwest and the western plains.

If the zonal circulations can be shifted from north to south in their general movement, so that for the period suggested, ca. 550 years, they have primarily high or low zonal movements, what is the controlling mechanism, and how is the suggested periodicity explained? If additional and more careful analysis and synthesis of the available paleoclimatic data tend to substantiate the pattern proposed here, then, presumably, the total air circulation patterns of the world must have produced this effect. Similar climatic shifts should be discernible in other areas where temperature and drought have been controlling factors in vegetational growth, with resultant affect upon human culture. One should be able to predict, for example, the periods at which north and northwestern China were favorable for agricultural production and which were not, and the periods during which the Mediterranean basin and North Africa were most favorable for agriculture and extensive human occupancy. It would be rather interesting to know. 


\section{References}

Antevs, E. 1955. Geologic-climatic dating in the West. Am. Antiquity. 20(4). Pt. 1. $: 317-335$.

Barendsen, G. W., E. S. Deevey \& L. J. Gralenski. 1957. Yale radiocarbon measurements III. Science. 126: $908-979$.

BARGHOORN, E. S. 1955. Paleobotanical studies in salt marsh deposits with special reference to recent changes in sea level. In Proceedings, Salt Marsh Conference. : 109-110. The Marine Institute. Univ. Georgia. Athens, Ga.

Benningmoff, W. S. 1942. The pollen analysis of the Lower Peat, in the Boylston Street fishweir. Papers of the R. S. Peabody Foundation for Archaeology. 2: 96-104.

FairbridGe, R. W. 1958. Dating the latest movements of the Quaternary sea level. Trans. N. Y. Acad. Sci. Ser. II. 20(6): 47-482.

GodwIN, H. \& E. H. WILLIS. 1959. Cambridge University natural radiocarbon measurements I. Am. J. Sci. Radiocarbon Suppl. 1: 63-75.

GodwIN, H. \& E. H. Willis. 1960. Cambridge University natural radiocarbon measurements II. Am. J. Sci. Radiocarbon Suppl. II: 62-72.

GrIfFIN, J. B. 1943. The Fort Ancient Aspect: Its cultural and chronological position in Mississippi Valley archaeology. Univ. Mich. Press. Ann Arbor, Mich.

Griffin, J. B., (Ed.) 1952. Archaeology of Eastern United States. Chicago Univ. Press. Chicago, Ill

GrIFFIN, J. B, 1958. The chronological position of the Hopewellian culture in the Eastern United States. Anthropological Papers, No. 12, Museum of Anthropology. Univer. Mich. Ann Arbor, Mich.

Griffin, J. B. $1960 a$. Climatic change: a contributory cause of the growth and decline of northern Hopewellian culture. Wis. Archaeologist. 41(1): 21-33.

Grifrin, J. B. 1960b. A hypothesis for the prehistory of the Winnebago. In Culture in History, S. Diamond, Ed. : 809-868. Columbia Univ. Press. New York, N.Y.

HAynes, V. \& G. AGOGINO. 1960. Geological significance of a new radiocarbon date from the Lindenmeier Site. Proceedings No.9, Denver Museum of Natural History. Denver, Colo.

Jennings, J. D., (Ed.) 1955. The American Southwest: A problem in cultural isolation. In Seminars in Archaeology. : 59-127. Memoir II, Society for American Archaeology. Salt Lake City, Utah.

Johnson, F. S. 1942. The Boylston Street Fishweir. Papers of the R. S. Peabody Foundation for Archaeology, Vol. 2, Andover.

Johnson, F. S., (Ed.) 1949. The Boylston Street Fishweir II. Papers of the R. S. Peabody Foundation for Archaeology. 4(1), Andover.

Kentev, J. C. 1956. Settlement Patterns in North-central Mexico. In Prehistoric Settlement Patterns in the New World, G. R. Willey, Ed. Viking Fund Publications in Anthropology. No. 23: 128-139. New York, N.Y.

Ritchie, W. A. 1958. An Introduction to Hudson Valley Prehistory. New York State Museum and Science Service Bull. No. 367. Albany, N.Y.

Rirchie, W. A. 1932. The Lamoka Lake site: The type station of the Archaic Algonkin period in New York. Researches and Trans. N. Y. State Archeological Assoc. 7(4): 79-134.

Robbins, M. 1959. Wapanucket No. 6: An archaic Village in Middleboro, Massachusetts. Cohannet Chapter, Mass. Archaeological Soc.

Rouse, I. 1951. A survey of Indian River Archeology, Florida. Yale University Publications in Anthropology, No. 44. New Haven, Conn.

SchofIE LD, J. C. 1960 . Sea level fluctuations during the last 4000 years as recorded by a Chenier Plain, Firth of Thames, New Zealand. New Zealand. Geol. Geophys. 3(3): 467-485.

SOPER, J. H. 1956. Some families of restricted range in the Carolinian flora of Canada. Trans. Roy. Can. Inst. XXXI, Pts. II. : 67-90.

WEDEL, W. S. 1941. Environment and native subsistence economies in the central Great Plains. Smithsonian Miscellaneous Collections. 101(3): 1-29.

Wedel, W. S. 1953. Some aspects of human ecology in the Central Plains. Am. Anthropologist. 55(4): 499-514. 